\title{
Relationships between male secondary sexual traits, physiological state and offspring viability in the three-spined stickleback
}

\author{
Violette Chiara*, Alberto Velando and Sin-Yeon Kim
}

\begin{abstract}
Background: Sexual signals produced by males play a central role in sexual selection, but the relationship between these traits and the quality of the bearer are often ambiguous. Secondary sexual traits may represent genetic quality of the bearer, resulting in positive relationships with physiological state, or may be costly to produce, showing tradeoff with physiological state. A number of studies have explored the relationships between secondary sexual traits and other functional traits, but few have studied their fitness consequences. We studied the link between diverse physiological traits and both morphological and behavioural sexual traits and examined how their interplay influences offspring viability in the three-spined stickleback.

Results: Male sticklebacks showing nest building and courtship behaviour were smaller than those not investing in reproductive activities. There was no evidence that the expression of red nuptial colouration and the quality of courtship behaviour of males are positively related to their metabolic rates, swim ability, oxidative damage and mtDNA copy number. However, individuals showing larger red nuptial colour areas had higher levels of oxidative DNA damage in their sperm. Male courtship behaviour and aggressiveness, but not red colour area, were good predictors of offspring hatching and survival.

Conclusions: Our results suggest that, in our study population at the southern edge of the species' distribution, sexual colouration of male sticklebacks was not a good indicator of their body state, but both courtship quality and aggressiveness during the courtship are reliable cues of their gamete quality, influencing the viability of their offspring. Thus, females that choose mates based on their courtship behaviour will have high fitness. In the study population, which represents a fast pace-of-life with high reproductive rate and short lifespan, sexual ornaments of males may not honestly signal their physiological and physical state because they invest at maximum in a single reproductive season despite high costs.
\end{abstract}

Keywords: Courtship, Genetic quality, Good-genes, Life history, Oxidative damage, Stickleback, Sexual selection

\section{Background}

The presence and maintenance of elaborated secondary sexual traits has been commonly linked with direct or indirect fitness advantages for choosy individuals, typically females [1]. In some cases, secondary sexual traits

*Correspondence: violette.chiara@gmail.com

Grupo Ecoloxía Animal, Torre CACTI, Centro de Investigación Mariña,

Campus de Vigo, Universidade de Vigo, 36310 Vigo, Spain and female preference can evolve through direct benefits if, for example, ornament size and colour reflect the state of the bearer [2]. Indeed, large or colourful ornaments of males are often associated with good internal state related to adequate alimentation [3-6], absence of parasitism or disease, or better immune response [7-11], thereby enhancing offspring viability through parental care [12, 13] (but see [14]). According to the "good genes" and "sexy sons" hypotheses, choosy females may also gain 
indirect fitness benefits through better genetic quality and attractiveness of their offspring (see $[15,16]$ ). However, the relationships among sexual traits, physiological condition and genetic quality of males are often different across studies, and it is still unclear how the interplay between these male qualities influences their offspring [17].

Some studies have explained variation among males in secondary sexual traits using the concept of a fast-slow life-history continuum. Fast-living individuals invest more in sexual ornaments or weapons and benefit from increased mating success or higher dominance status [18] but have shorter life span than slow-living individuals that invest less in these sexual traits [19-21]. This is because the expression and maintenance of sexual traits are costly and divert resources away from other functional traits of the bearers, including somatic maintenance $[16,19]$. These trade-offs between sexual traits and internal states may be mediated by energy expenditure and metabolism (see [22] for a review). The maintenance of sexual characters may require increased energy metabolism. For instance, resting metabolic rate is positively correlated with prenuptial gland size in male bank voles [23] and with sexual colouration in male and female American goldfinches [24]. One way to meet energetic demands of expressing secondary sexual traits may be increasing mitochondrial DNA (mtDNA) copy number in somatic cells to enhance cellular energy production. In fishes, reduced mtDNA copy number is associated with a dysfunction of mitochondrial activity in aged $[25,26]$ and larva fish [27], but it is unknown whether mitochondrial function can also influence the expression of sexual traits.

Long-term expression and maintenance of energetically costly sexual traits may result in an increased risk of oxidative damages. Normal metabolic processes generate reactive by-products, which induce oxidative damages in DNA, proteins and lipids [28, 29]. Some empirical studies have shown that males investing heavily in secondary sexual traits not only suffer accelerated somatic deterioration [30] but also fail to maintain germ cells free of damage [29,31]. Deleterious oxidative damages in the soma reduce the individual's lifespan and future reproduction opportunities [32], and those in the germline can affect the immediate reproductive success by reducing fertility and offspring viability [29, 33-36].

Courtship displays are energetically costly secondary sexual traits. Metabolic rate can increase up to fourfold during courtship in the wax moth [37] and up to three-fold during singing in the Carolina wren [38] (for a review, see [39]). Although the energetic cost of a single courtship event may be almost negligible in comparison to the daily energy budget of an individual [39], there is evidence of long-term energetic costs and time costs of courtship in various species $[40,41]$. Thus, the quality and intensity of courtship display of a male may honestly signal its physiological condition or genetic quality. Indeed, in Sierra dome spiders the quality of energetically costly courtship is related to the male's metabolic rate [42]. In golden-collared manakins, females seem to select their mate on the basis of metabolic competence and courtship quality of males is related to their heart rate [43]. Thus, physical performances and maximum metabolic rate of a male may predict its courtship quality [39]. In species in which males defend a territory and build a nest, the quality of nest or territory may also represent time and energy expenses of the male [41, 44]. Females can predict a male's quality through its aggressiveness because this characteristic is related with the ability to protect offspring and to access resources in competitive environment $[45,46]$. However, highly aggressive males may also harass females during courtship, decreasing their attractiveness (e.g., [47]). In fishes where males provide parental care, highly aggressive males should be avoided by females because high levels of aggressioninducing hormones (androgens) are related to reduced parental behaviours [48].

Here, we studied the link between physiological state and sexual signalling and examined how their interplay influences offspring viability in the three-spined stickleback (Gasterosteus aculeatus). We used a stickleback population at the southern edge of its distribution, which represents a fast pace-of-life with high reproductive rate and short lifespan. In this species, including our study population, males defend a territory, build a nest, provide paternal care, and express red nuptial colouration on their cheek and throat based on dietary carotenoids. This colouration is known to represent physical condition of males $[49,50]$ but incurs costs in terms of predation risk [51] and oxidative damage [29, 52]. Male sticklebacks perform highly stereotyped courtship displays, which represent their parenting qualities [13]. Males whose courtship was associated with aggressive behaviour are avoided by females [47]. In this study, we first studied whether different characteristics of the physiological state of male sticklebacks, including standard and maximum metabolic rates, swim ability, oxidative DNA damage in sperm, and mtDNA copy number in muscle, are related with their secondary sexual traits, such as nest, courtship behaviour, aggressiveness, and size of red nuptial colour area. Finally, we examined whether the physiological and sexual traits are good predictors of the offspring survival.

\section{Results}

Secondary sexual traits and physiological states

Among 29 males used in this study, 20 built a nest during the study period, and 18 of these succeeded to 
reproduce repeatedly. Fish with a nest were smaller in standard length than those without a nest (standard length: $\mathrm{t}=2.964, \mathrm{df}=13.581, \mathrm{P}=0.011$; Additional file 1 : Table S1). Fish with and without a nest did not differ in residual standard metabolic rate (rSMR), residual maximum metabolic rate (rMMR), critical swimming speed $\left(U_{\text {crit }}\right)$, the level of oxidative DNA damage in sperm and mtDNA copy number in muscle ( $\mathrm{P} \geq 0.323$; Additional file 1: Table S1). We assessed courtship quality and aggressiveness of all males that reproduced in a courtship behaviour assay. In these fish, courtship quality was negatively correlated with body weight $\left(\mathrm{F}_{1 ; 12}=6.498\right.$, $\mathrm{P}=0.023$, Fig. $1 \mathrm{~A})$, but heavier fish had a larger relative red area $\left(\mathrm{F}_{1 ; 12}=4.685, \mathrm{P}=0.051\right.$, Fig. $\left.1 \mathrm{~B}\right)$. Courtship quality, aggression and relative size of red colour area were not related to rSMR, rMMR, $U_{\text {crit }}$, mtDNA copy number and body weight $(\mathrm{P} \geq 0.078$; Additional file 1 : Table S2). Oxidative DNA damage in sperm was not correlated with the levels of courtship and aggressiveness in males that reproduced (courtship: $\mathrm{F}_{1 ; 14}<0.01, \mathrm{P}=0.991$; aggressiveness: $\mathrm{F}_{1 ; 14}<0.01, \mathrm{P}=0.948$ ), but males with a larger relative red area showed a higher level of oxidative DNA damage in sperm (Fig. $1 \mathrm{C}, \mathrm{F}_{1 ; 14}=8.48, \mathrm{P}=0.011$ ). The level of oxidative DNA damage was not related to any other body state variables measured $(P \geq 0.130$, Additional file 1: Table S3).

\section{Offspring hatching and survival}

Mean clutch size $( \pm S D)$ was $53.207 \pm 9.998$, mean hatching rate was $89.586 \pm 9.878 \%$, and mean survival rate of hatched larvae until age 10 days was $50.528 \pm 39.581 \%$ ( $N=29$ families). The hatching success was not repeatable within males, while the survival rate was highly repeatable (hatching: $\mathrm{R}=0.011 \quad[0-0.066] \quad 95 \% \quad \mathrm{CI}$, $\mathrm{P}=0.341$; survival: $\mathrm{R}=0.610 \quad[0.353-0.757] \quad 95 \% \mathrm{CI}$, $\mathrm{P}<0.001$; overall survival: $\mathrm{R}=0.579[0.315-0.744] 95 \%$ CI, $\mathrm{P}<0.001$; see Additional file 2: Fig. S1).

Aggressiveness and courtship quality of fathers, which were measured in a courtship behaviour assay, predicted hatching and survival of larvae (Fig. 2). The males displaying aggressive behaviours during the courtship test had reduced offspring hatching and survival rates (hatching: $\mathrm{P}=0.005$; survival: $\mathrm{P}=0.036$; overall survival: $\mathrm{P}=0.030$; Additional file 1: Table S4). The males performing better courtship showed higher offspring survival rates (survival: $\mathrm{P}=0.010$; overall survival: $\mathrm{P}=0.007$; Additional file 1: Table S4). There was no statistically significant relationship between relative size of red colour area of fathers and hatching and survival of larvae $(P \geq 0.271$; Additional file 1: Table S4). rMMR of father was negatively correlated to hatching rate of offspring $(\mathrm{P}=0.050$; Additional file 1: Table S4), but other body state traits of males were not related to larvae hatching or survival ( $\mathrm{P} \geq 0.074$; Additional file 1: Table S4).

The principal results are summarised in Additional file 1: Table S5.

\section{Discussion}

In this study, we examined whether secondary sexual traits of male three-spined sticklebacks from a fastliving population are related to their body state traits, as frequently assumed, and tested whether these traits influence the viability of their offspring. Individuals investing in nest construction and courtship behaviour were smaller than those not investing in these reproductive activities. However, there was no evidence that the
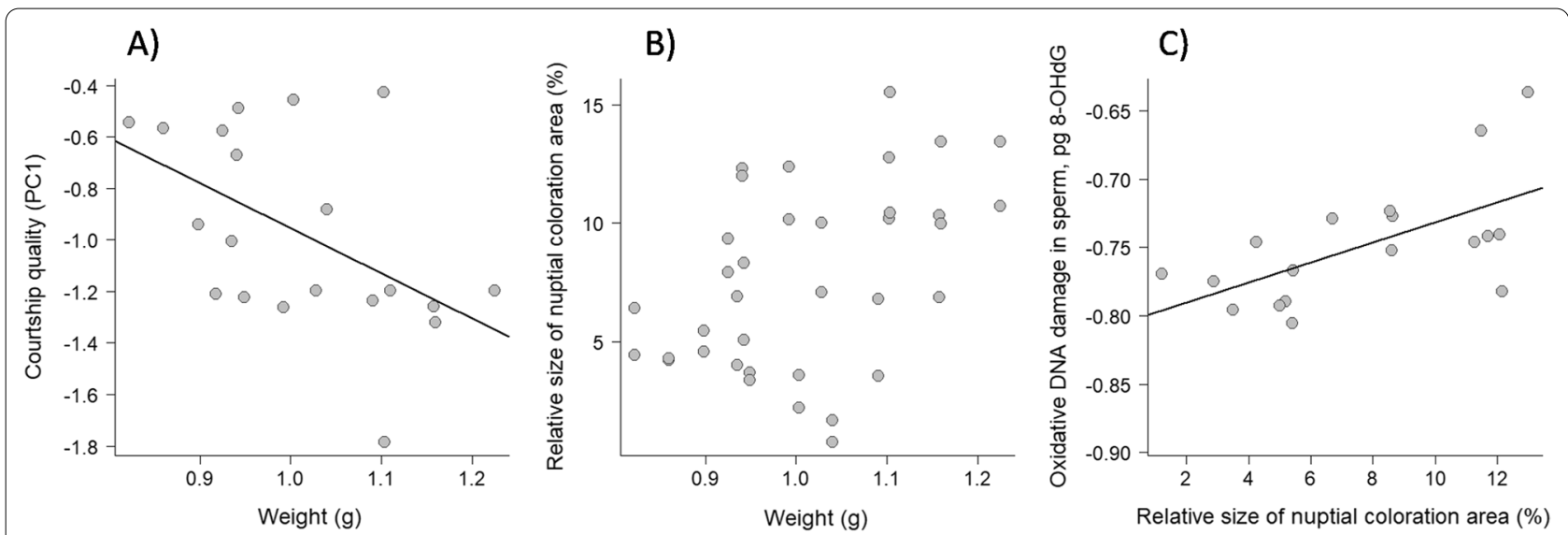

Fig. 1 A Relationship between body weight and the quality of courtship in males with a nest $(N=20)$. B Relationship between body weight and relative size of red colour area ( $\mathrm{N}=36$ measurements, $\mathrm{N}=18 \mathrm{fish}$ ). C Relationship between relative size of nuptial colour area and the level of oxidative DNA damage in sperm $(N=18)$. Courtship and oxidative DNA damage in sperm are transformed values. Regression lines are presented for significant relationships $(P<0.05)$ 

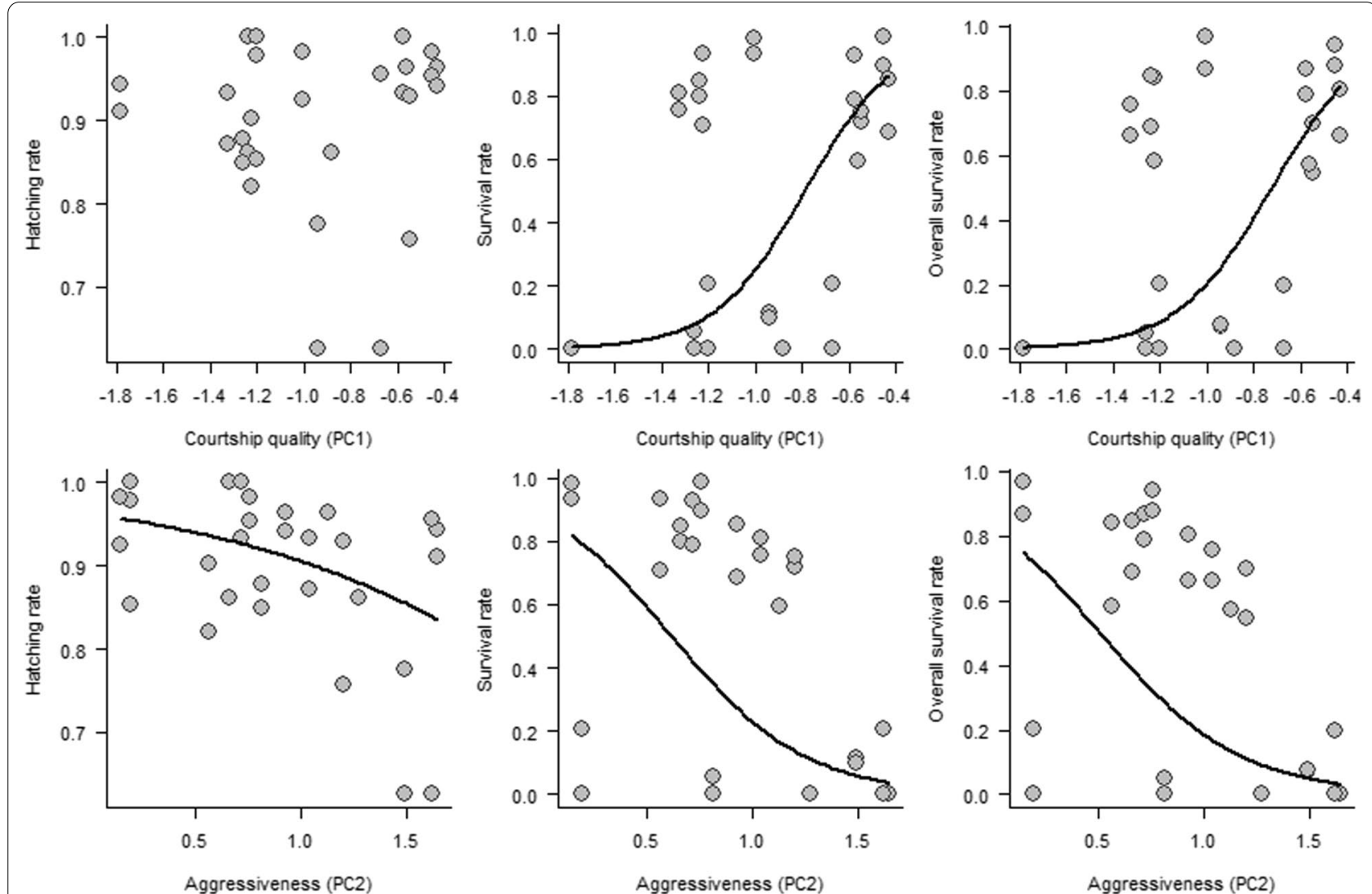

Fig. 2 Hatching (first column), survival after hatching (second column), and overall survival considering both hatching and survival rates (third column) of full-sibling families ( $\mathrm{N}=29$ ) as a function of the courtship quality (first row) and aggressiveness (second row) of fathers expressed during the courtship assay. Aggressiveness and courtship quality are the transformed values. Regression lines are presented for significant relationships $(P<0.050)$

expression of secondary sexual traits (i.e., red colouration and courtship behaviour) represent the physical and physiological status of males (i.e., metabolic rates, swim ability and mtDNA copy number). Fish investing more in red nuptial colouration showed higher levels of oxidative DNA damage in their sperm, confirming previous evidence that the expression of red colouration trades off against sperm quality in this population (see [29]). Male behaviours during courtship, but not red colouration, were good predictors of offspring viability.

Previous studies of different three-spined stickleback populations have demonstrated positive correlations between secondary sexual traits and male condition. For instance, redder males are relatively heavier to their size $[3,50]$, have more lipids contents [49] or are less parasitized than duller males [50]. In this study where we explored a variety of physiological and physical measures of male state in an annual stickleback population, we found no evidence that the size of the nuptial area and courtship behaviours of males honestly signal their physiological and physical condition. Although small sample size in this study perhaps limited the statistical power to detect any small effect, these results are in accordance with previous studies using the same population that showed trade-offs between the expression of secondary sexual or other reproductive traits of males and staterelated traits either at the phenotypic or at the genetic level. In the study population, redder males carried more oxidative DNA damage in the soma and germline [29], and males simultaneously upregulated metabolic and oxidation-reduction genes and downregulated reproduction-related hormone genes in response to an environmental challenge [53]. The expression of red nuptial colouration has heritable variation in our study population [36], so females may gain indirect benefits if they preferentially mate with a redder male (but see below).

The "good genes" process implies the presence of positive associations between secondary sexual traits and the bearer's genetic quality [54]. On the other hand, sexual ornaments are costly to produce and maintain $[16,19]$. Our results show that the investment of males in red colouration and other reproductive activities incurred 
oxidative costs. These trade-offs may occur because, for example, sexual signalling based on carotenoids diverts these resources away from other important physiological functions such as antioxidant protection of the soma and germline during growth and reproduction $[29,55]$. Carotenoid rich diet appears to increase the quality of parental care in sticklebacks [56], suggesting that red colouration can also compete with this function. These costs may limit the expression of red colouration and reduce the honesty of this signal as an indicator of mate quality [51]. Indeed, in a recent study, we found that the level of oxidative DNA damage in sperm negatively influenced egg fertilization success in the same study population (our unpublished data). It is interesting to note that juveniles from redder families tend to die younger in this population due to genetic conflict between attractiveness and viability [36], and females do not prefer redder males in another adjacent annual population [57]. Nevertheless, red colouration may be selected due to its benefits for male sticklebacks in territory defence against other males $[58,59]$. It is important to note that we used relative size of red area as a measure of nuptial colouration, but using different measures of this sexual signal, for example colour intensity, may lead to different results [60-62].

Fitness consequences of sexual traits are often explored to demonstrate the interplay between sexual traits and genetic quality, and positive correlations between sexual ornaments and offspring survival have been found in a wide range of species including both vertebrates and invertebrates [63-68]. However, few studies have considered courtship behaviours as sexual traits to explore their effects on offspring survival [69, but see 70]. Although there was no evidence that courtship quality and aggressiveness of male sticklebacks are correlated with their physiological and physical state, these male behaviours were closely related to the viability of their offspring. Offspring sired by males that perform better courtship and show less aggression toward their mates hatched and survived better, although hatching rate was not repeatable within males. In species where males provide intensive parental care, like the three-spined stickleback, it is difficult to disentangle the effect of genetic quality and parental care on offspring survival [13, 71]. Stickleback males of good quality that show better courtship and less aggression are also likely to provide better care for eggs and larvae and not predate on their offspring [13]. In this study, the fertilised eggs were separated from their fathers then incubated under standardised conditions to remove parental care effect, but offspring survival rate was still highly repeatable within males and correlated with male's behaviours. Thus, our results demonstrate that aggressiveness and courtship behaviour can signal the genetic quality of male sticklebacks, with strong consequences for offspring viability, which are not attributed to parental care.

Our results suggest that both courtship quality and aggressiveness of males during the courtship are reliable cues of their genetic quality. Thus, females that choose mates based on males' courtship behaviours might have high fitness. Indeed, aggressive males have a lower probability to successfully mate with a receptive female in the three-spined stickleback [47]. It is interesting to note that our study population located at the southern edge of the species' European distribution presents a fast pace-oflife. In this annual population, fish go through a single long reproductive season during which females spawn on average six clutches [72], and successful males simultaneously take care of multiple clutches from different females in their nests [73]. Thus, males' behaviours during courtship, which are related to their cognitive ability [57] and possibly to their parental care behaviour, may be under strong sexual selection in this population. Contrary to expectations, in these annual populations, sexual ornaments of males may not honestly signal their physiological and physical state because they invest at maximum in the single reproductive season due to their relatively low life expectancy compared to northern populations [13, 74].

\section{Conclusions}

We show that sexual signals of male sticklebacks were not a good indicator of their body state, but their aggressiveness predicted offspring viability. In the study population, which represents a fast pace-of-life with high reproductive rate and short lifespan, individuals may invest all their resources in a single reproductive season despite high costs, and thus sexual colouration may not honestly signal their state. Our results suggest that courtship behaviour of a male is a good indicator of its genetic quality that influences offspring viability. Thus, in our study population, we expect that females will increase fitness by choosing males performing good courtship instead of those investing heavily in sexual colouration.

\section{Methods}

\section{Study population and maintenance}

On 10th March 2020, we collected wild adult threespined sticklebacks with hand nets in the Rio Sar (Galicia, Spain). The fish were brought to the lab and maintained individually in 8-L tanks randomly distributed in three closed flow-through water systems. In these three systems, water was filtered and aerated by mechanical filters and circulation pumps. Visual contact between fish was prevented by opaque lateral walls. Flow-through water coolers ensured that the water temperature matched the seasonal water temperature in the sampling site 
$\left(14{ }^{\circ} \mathrm{C}\right)$. Natural photoperiod was simulated too with programmed lighting (13 h light: $11 \mathrm{~h}$ dark cycle). Tanks were enriched with an artificial plant and a shelter made of a PVC pipe (see Additional file 2: Fig. S2). Fish were fed daily on defrosted bloodworms.

We provided 29 male fish housed in individual tanks with nesting materials, a Petri dish filled with sand and a bunch of 50 green polyester threads (Additional file 2: Fig. S2). Once a fish used all the threads for nesting, more threads were provided until the nest was completed (with a visible entrance hall). Females were monitored daily to record gravidity, which is evident from abdomen size and cloaca opening. To stimulate nest constructions, all males were shown a gravid female enclosed within a transparent glass during 5 min three times per week from 25th March, then once a day from 4th May (i.e., during the peak breeding season) until used for reproduction (see below). Each female was presented to a maximum of six fish per day and was not used for two consecutive sessions (i.e., at least 4-day intervals between two presentation sessions).

\section{Fish reproduction}

During the peak breeding season, males who constructed a nest were used for reproduction (20 out of 29 males) with two different mates. Among these, 18 succeed to mate and produced two fertilized clutches between 27th April and 25th May ( $\mathrm{N}=36$ full-sib families). A breeding session began by releasing a fully gravid female (evident from cloaca opening) inside a male's tank and lasted up to $30 \mathrm{~min}$. The female was removed if one of the pair presented a highly aggressive behaviour toward the other, or if the male did not display any courtship within $5 \mathrm{~min}$. Once a female spawned and the eggs were fertilized by her mate, she was returned to her home tank. One hour after fertilization, the whole clutch was carefully collected from the nest and placed in an incubator. Then, to assess the male's nuptial colouration, it was photographed on its left side with a digital camera (Nikon D90) under standardized conditions by following a standard method [3, 49]. For this, the male was immobilized within a transparent plastic box filled with water by using a black sponge. The whole process of fish handling took less than $90 \mathrm{~s}$. We calculated the proportion of the fish lateral area coloured in red by analysing the digital image with a homemade program coded in python and using the open-cv library. The periphery of the fish was manually trimmed and we calculated the proportion of pixels included in given hue, saturation and value ranges (Hue: 340-360 and 0-50; Saturation: 100-255; Value: 0-255).

The 36 fertilized clutches were housed in an 65-L incubation tank, which was well-aerated with several air stones, following standard egg husbandry protocol [75].
One day before hatching (7 days after fertilization), each clutch was transferred to a 10-L tank and provided with three drops of industrial liquid food for newly-hatched larvae (NobilFluid Artemia, JBL $\odot$ ). Two days after hatching (day 2), we began to feed the stickleback larvae twice a day with newly hatched Artemia. At day 4, we counted the numbers of alive and dead larvae and unhatched eggs to determine hatching success (i.e., the proportion of eggs hatching and producing viable larvae). The survival of larvae was monitored daily until age 10 days, and dead individuals were removed. In the tanks, the water oxygenation was ensured with an air stone until day 5 , after which the air stone was replaced by a sponge filter. Unfortunately, accidental mortalities occurred due to a temporal failure of air supply in six tanks, and these six out of 36 full-sib families have been excluded from the data analyses.

\section{Courtship behaviour}

We assessed the quality of courtship behaviour of all males with a nest $(\mathrm{N}=20)$ on 27 th May. Prior to this, all males were exposed daily to a gravid female in the same way as above. For each courtship assay, we presented a gravid female enclosed within a glass in the top right corner of the male tank, allowing visual but not physical contacts between fish (see Additional file 2: Fig. S2), and video-recorded the fish for three minutes using a digital camera (Nikon 90D). Each female was used for up to 6 assays. After the courtship assay, males were weighed with a digital balance (precision $0.001 \mathrm{~g}$ ) and measured with a metal ruler (precision $0.05 \mathrm{~cm}$ ). The videos were analysed by an experimenter, blind to the fish identity, using the BORIS software [76]. For each focal male we recorded the occurrences of five different behaviours: leading to the nest (when it faces the female and immediately after swims toward his nest or nesting materials), fanning (while facing the nest, it increases the rate of flapping his pectoral fins, simulating egg ventilation), showing nest entrance (when it inserts its head into the nest entrance and performs small "back and forth"), gluing (when it passes over the nest, rubbing its belly, simulating nest building), and aggression (when it dashes violently toward the female with its mouth open).

\section{Metabolic rate and swimming performance measurements} Metabolic rates and swimming performance were examined between 29th May and 06th June in all males, both with and without a nest $(\mathrm{N}=29)$. We first measured the standard metabolic rate (SMR) of fish by using an intermittent-flow mini-chamber respirometer system (Loligo Systems, Viborg, Denmark), which simultaneously measured the oxygen consumption of four different fish during an 18 -h session. We used a standard protocol described 
in the (Additional file 3: S1). After the SMR session, the four fish were moved from the respirometer chambers to individual waiting tanks (similar to their home tanks) before the measurements of their maximum metabolic rates (MMR) and swimming performances (critical swimming speed, $U_{\text {crit }}$ ) in an intermittent-flow swim tunnel respirometer system (Loligo Systems). We used a standard protocol described in the (Additional file 3: S2). After the measurements of SMR, MMR and $U_{\text {crit }}$, the fish were euthanized with an overdose of benzocaine anaesthetic.

The sacrificed fish $(\mathrm{N}=29)$ were dissected to extract their left testis as well as a part of their dorsal muscle. Testis was cut into small pieces in $50 \mu \mathrm{l}$ of buffer and gently agitated with a Vortex mixer to separate sperm from the testis tissue, and then the sperm solution was collected. The sperm and muscle samples were kept at $-80^{\circ} \mathrm{C}$ until further use.

\section{Oxidative DNA damage in sperm and mtDNA copy number in muscle}

The relative mtDNA copy number in muscle was estimated by calculating the ratio of mtDNA on nuclear DNA by real-time PCR on a StepOnePlus (Applied Biosystems). The details of the analysis are presented in the (Additional file 3, S3). The level of oxidative damage in sperm DNA was estimated by measuring the quantity of 8-hidroxy-2-deoxyguanosine (8-OHdG, an oxidized derivative of deoxyguanosine). The level of oxidative DNA damage was expressed as quantity in picograms of genomic DNA containing 8-OHdG. The details are presented in the (Additional file 3, S4).

\section{Data analyses}

All the following statistical analyses were done with the $\mathrm{R}$ software ( $\mathrm{R}$ version 4.0.3). Five different behaviours recorded during the courtship test in males with a nest were first analysed by a principal component analysis (PCA, $\mathrm{N}=20)$ using the FactoMineR package. The first principal component (PC1) explained $74.39 \%$ of the variance and regrouped equally four typical courtship behaviours (i.e., leading to the nest, fanning, showing nest entrance, and gluing). These four behaviours appeared to be highly correlated to each other, suggesting that they carried redundant information (Additional file 1: Table S6). The second component (PC2) explained $19.43 \%$ of the variance and was composed with $97.06 \%$ of the attack behaviour during the courtship assay (Additional file 2: Fig. S3). Thus, in the subsequent analysis, we used PC1 and PC2 (hereafter, "courtship quality" and "aggressiveness").

Residuals from the regression models, relating SMR and MMR to body mass (measured immediately after metabolic rate measurement), were used as standardized metabolic rates (respectively rSMR and rMMR) in all statistical analyses [77]. rMMR, oxidative DNA damage in sperm, and behaviours (PC1 and PC2) were transformed with the transformTukey function from the package rcompanion [78] prior to the analyses to satisfy the linearity and homoscedasticity criteria: transformed rMMR equals $-1 \times(\mathrm{rMMR}+1)^{-0.1}$, transformed oxidative DNA damage in sperm equals $-1 \times \mathrm{DNA}_{\mathrm{dam}}{ }^{-0.2}$, transformed $\mathrm{PC} 2$ equals $(\mathrm{PC} 2+1)^{0.425}$, transformed $\mathrm{PC} 1$ equals $-1 \times(\mathrm{PC} 1+2)^{-0.45}$.

We tested whether courtship quality and aggressiveness ( $\mathrm{PC} 1$ and $\mathrm{PC} 2)$ were related to physiological state (weight, rSMR, rMMR, $U_{\text {crit }}$, and mtDNA copy number) in males with a nest $(\mathrm{N}=20)$ by using two linear models (LMs), containing all the physiological traits as independent variables. Since red colour area was measured repeatedly (immediately after successful mating, $\mathrm{N}=18$ fish), the relationships between physiological traits and relative size of red colour area were analysed in a linear mixed effect (LME) model with male identity as a random factor. We analysed the relationships between sexual traits (courtship, aggressiveness and averaged red colour area) and the level of oxidative DNA damage in sperm by using a LM (dependent variable: sperm DNA damage, $\mathrm{N}=18$ ). In another LM, the relationships between body state variables (rMMR, rSMR, $U_{\text {crit }}$, mtDNA copy number and weight) and oxidative DNA damage in sperm were explored $(\mathrm{N}=20)$.

We examined whether hatching rate (proportion of eggs hatching) and survival rate (proportion of hatched larvae surviving to age 10 days) of offspring were repeatable within fathers by using the rpt function of the rptR package [79]. The models included the father identity as a grouping factor and the order of reproduction (first or second clutch) as a fixed effect. One family out of 30 full-sib families was excluded in the statistical analyses because it had an extremely low hatching rate $(<10 \%$, an outlier).

We tested whether fathers' physiological traits influenced offspring hatching, survival to age 10 days and overall survival (proportion of eggs successfully hatching and surviving to age 10 days) using the glmer function (lme4, $\mathrm{R}$ package) in generalized linear mixed models (GLMMs) with a binomial error distribution and a logit link function. In the models, parents' identities were included as random effects, father's weight, oxidative DNA damage in sperm, rSMR, rMMR, $U_{\text {crit }}$ and mtDNA copy number in muscle as fixed effects without interactions. The effects of males' secondary sexual traits (courtship quality, aggressiveness and red colour area) on offspring hatching and survival were also analysed in GLMMs, including parental identities 
as random variables and red colour area, courtship quality and aggressiveness as fixed effects.

\begin{abstract}
Abbreviations
Cl: Confidence interval; DNA: Deoxyribonucleic acid; GLMM: Generalized linear mixed model; LM: Linear model; LME: Linear mixed effect model; MMR: Maximum metabolic rate; mtDNA: Mitochondrial DNA; PCA: Principal component analysis; PCR: Polymerase chain reaction; PVC: Polyvinyl chloride; rMMR: Residual maximum metabolic rate; rSMR: Residual standard metabolic rate; SMR: Standard metabolic rate; $U_{\text {crit: }}$ Critical swimming speed; $8-O H d G$ : 8-Hidroxy-2-deoxyguanosine.
\end{abstract}

\section{Supplementary Information}

The online version contains supplementary material available at https://doi. org/10.1186/s12862-021-01958-8.

Additional file 1: Table S1.Results of t tests and Wilcoxon test for the comparisons of body state traits between the males that built a nest and those that did not. Table S2. Results of the LMEs (red coloration) and LMs (courtship and aggressiveness) testing for the effects of physiological traits on the secondary sexual traits. Table S3. LMs testing the effects of secondary sexual traits on oxidative DNA damage in sperm. Table S4. Results of the GLMMs testing the effects of body state and sexual traits of fathers on egg hatching success, and offspring survival. TableS5. Summary of the main effects (statistically significant results) found in our analyses. Table S6. Coefficient of correlation ( $r$ ) between different behaviours of males measured during the courtship. Values in bold indicates significant correlation with $\mathrm{P}<0.05$. The correlations are done between the number of occurrences of each behaviour.

Additional file 2: Figure S1. a) Hatching success, b) survival rate after hatching and c) overall hatching and survival rate of different clutches sired by different males. The father identity is indicated in the $x$-axes; fathers are ordered according to the mean hatching/survival rate. Figure S2. A male's tank during female presentation. (A) Male, (B) gravid female within a glass, (C) artificial plant, (D) PVC shelter, and (E) nest materials (Petri dish filledwith sand, and threads). Figure S3. Principal Component Analysis (PCA) of themale's behaviours during the courtship test. a) PCA graphic of the variables and b) summary of the contributions of the different variables to the two different axis.

Additional file 3: S1. Standard metabolic rate estimation. S2. Maximum metabolic rate and swimming performance protocols. S3. Measurements of mtDNA copy number in muscle. S4. Measurement of oxidative DNA damage in sperm.

\section{Acknowledgements}

We are grateful to Alberto da Silva, Náyade Álvarez-Quintero and Pedro Campoy for their help during the study.

\section{Authors' contributions}

VC carried out the experiments, participated in the design of the study, in statistical analyses and in manuscript redaction. AV analysed and interpreted the data regarding the DNA oxidative damages and participated in the manuscript redaction. S-YK coordinated the whole process, participated in experiments, in the design of the study, in statistical analyses and in manuscript redaction. All authors read and approved the final manuscript.

\section{Funding}

This work was supported by research Grants provided by the Ministerio de Ciencia, Innovación y Universidades (PGC2018-095412-B386 I00) and the Xunta de Galicia (ED431F 2017/07). V.C. was funded by the Fyssen Foundation grant, S.-Y.K. was supported by Ramón y Cajal fellowship from the Ministerio de Ciencia, Innovación y Universidades (RYC-2015-18317).

\section{Availability of data and materials}

The datasets supporting the conclusions of this article are included within the article and its additional files.

\section{Declarations}

Ethics approval and consent to participate

This study was reviewed and approved by the Animal Experiment Ethics Committee of the Universidade de Vigo (00012-19SYK) and the Xunta de Galicia (ES360570181401/19/FUN01/BIOL AN.08/SYK). The study was carried out in compliance with the ARRIVE guidelines.

\section{Consent for publication}

Not applicable.

\section{Competing interests}

The authors declare that they have no competing interests.

Received: 9 August 2021 Accepted: 22 December 2021

Published online: 07 January 2022

\section{References}

1. Andersson M. Sexual selection. Prinston: Princeton University Press; 1994.

2. Møller A, Jennions M. How important are direct fitness benefits of sexual selection? Naturwissenschaften. 2001;88:401-15.

3. Frischknecht $M$. The breeding colouration of male three-spined sticklebacks (Gasterosteus aculeatus) as an indicator of energy investment in vigour. Evol Ecol. 1993;7:439-50.

4. Ohlsson T, Smith HG, Råberg L, Hasselquist D. Pheasant sexual ornaments reflect nutritional conditions during early growth. P Roy Soc B-Biol Sci. 2002;269:21-7.

5. Uetz GW, Papke R, Kilinc B. Influence of feeding regime on body size, body condition and a male secondary sexual character in Schizocosa ocreata wolf spiders (Araneae, Lycosidae): condition-dependence in a visual signaling trait. J Arachnol. 2002;30:461-9.

6. Velando A, Beamonte-Barrientos R, Torres R. Pigment-based skin colour in the blue-footed booby: an honest signal of current condition used by females to adjust reproductive investment. Oecologia. 2006;149:535-42.

7. Møller AP, Christe P, Lux E. Parasitism, host immune function, and sexual selection. Q Rev Biol. 1999;74(1):3-20.

8. Mougeot F, Irvine JR, Seivwright L, et al. Testosterone, immunocompetence, and honest sexual signaling in male red grouse. Behav Ecol. 2004;15:930-7.

9. Peters A, Delhey K, Denk AG, Kempenaers B. Trade-offs between immune investment and sexual signaling in male mallards. Am Nat. 2004;164:51-9.

10. Clotfelter ED, Ardia DR, McGraw KJ. Red fish, blue fish: trade-offs between pigmentation and immunity in Betta splendens. Behav Ecol. 2007;18:1139-45

11. McGraw KJ, Hill GE. Differential effects of endoparasitism on the expression of carotenoid- and melanin-based ornamental coloration. P R Soc B-Biol Sci. 2000;267:1525-31.

12. Hill GE. Plumage coloration is a sexually selected indicator of male quality. Nature. 1991;350:337-9.

13. Candolin U. Changes in expression and honesty of sexual signalling over the reproductive lifetime of sticklebacks. P R Soc B-Biol Sci. 2000;267:2425-30.

14. Mitchell DP, Dunn PO, Whittingham LA, Freeman-Gallant CR. Attractive males provide less parental care in two populations of the common yellowthroat. Anim Behav. 2007;73:165-70.

15. Neff BD, Pitcher TE. Genetic quality and sexual selection: an integrated framework for good genes and compatible genes. Mol Ecol. 2005;14:19-38.

16. Bonduriansky R, Maklakov A, Zajitschek F, Brooks R. Sexual selection, sexual conflict and the evolution of ageing and life span. Funct Ecol. 2008;22:443-53. 
17. Long TAF, Agrawal AF, Rowe L. The effect of sexual selection on offspring fitness depends on the nature of genetic variation. Curr Biol. 2012;22:204-8.

18. Parker TH, Ligon JD. Dominant male red junglefowl (Gallus gallus) test the dominance status of other males. Behav Ecol Sociobiol. 2002;53:20-4.

19. Promislow DEL. Costs of sexual selection in natural populations of mammals. P R Soc B. 1992;247:203-10.

20. Vieira C, Pasyukova EG, Zeng ZB, et al. Genotype-environment interaction for quantitative trait loci affecting life span in Drosophila melanogaster. Genetics. 2000;154:213-27.

21. Hunt J, Brooks R, Jennions MD, et al. High-quality male field crickets invest heavily in sexual display but die young. Nature. 2004;432:1024-7.

22. Kotiaho JS. Costs of sexual traits: a mismatch between theoretical considerations and empirical evidence. Biol Rev Camb Philos. 2001;76:365-76.

23. Radwan J, Chadzińska M, Cichoń M, et al. Metabolic costs of sexual advertisement in the bank vole (Clethrionomys glareolus). Evol Ecol Res. 2006:8:859-69.

24. Kelly RJ, Murphy TG, Tarvin KA, Burness G. Carotenoid-based ornaments of female and male American goldfinches (Spinus tristis) show sex-specific correlations with immune function and metabolic rate. Physiol Biochem Zool. 2012;85:348-63.

25. Hartmann N, Reichwald K, Wittig I, Dröse S, Schmeisser S, Lück C, et al. Mitochondrial DNA copy number and function decrease with age in the short-lived fish Nothobranchius furzeri. Aging Cell. 2011;10:824-31.

26. Zhu S, Coffman JA. Simple and fast quantification of DNA damage by real-time $P C R$, and its application to nuclear and mitochondrial DNA from multiple tissues of aging zebrafish. BMC Res Notes. 2017:10:1-6.

27. Fan X, Wang L, Wei X, Zhang J, Su X, Cui L, et al. The impairment of continuous malnutrition on larval fish swimming performance at the mouth-opening stage. Aquaculture. 2021;544:737053.

28. Adelman R, Saul RL, Ames BN. Oxidative damage to DNA: relation to species metabolic rate and life span. P Natl Acad Sci USA. 1988;85:2706-8.

29. Preston $B T$, Jalme MS, Hingrat $Y$, et al. Sexually extravagant males age more rapidly. Ecol Lett. 2011;14:1017-24.

30. Tomášek O, Albrechtová J, Němcová M, et al. Trade-off between carotenoid-based sexual ornamentation and sperm resistance to oxidative challenge. P R Soc B-Biol Sci. 2017;284:20162444

31. Kim SY, Velando A. Attractive male sticklebacks carry more oxidative DNA damage in the soma and germline. J Evol Biol. 2020;33(1):121-6.

32. Luo J, Mills K, le Cessie $\mathrm{S}$, et al. Ageing, age-related diseases and oxidative stress: what to do next? Ageing Res Rev. 2020;57:100982.

33. Rajesh Kumar T, Doreswamy K, Shrilatha B, Muralidhara. Oxidative stress associated DNA damage in testis of mice: induction of abnormal sperms and effects on fertility. Mutat Res. 2002;513:103-11.

34. Aitken RJ, De luliis GN. Origins and consequences of DNA damage in male germ cells. Reprod Biomed Online. 2007;14:727-33.

35. Lane M, McPherson NO, Fullston T, et al. Oxidative stress in mouse sperm impairs embryo development, fetal growth and alters adiposity and glucose regulation in female offspring. PLOS ONE. 2014;9:1-9.

36. Kim SY, Velando A. Genetic conflict between sexual signalling and juvenile survival in the three-spined stickleback. BMC Evol Biol. 2016;16:1-7.

37. Reinhold K, Greenfield MD, Jang Y, Broce A. Energetic cost of sexual attractiveness: ultrasonic advertisement in wax moths. Anim Behav. 1998;55:905-13.

38. Eberhardt LS. Oxygen consumption during singing by male Carolina Wrens (Thryothorus /udovicianus). Auk. 1994;111:124-30.

39. Clark CJ. The role of power versus energy in courtship: what is the "energetic cost" of a courtship display? Anim Behav. 2012;84:269-77.

40. Lailvaux SP, Irschick DJ. A functional perspective on sexual selection: insights and future prospects. Anim Behav. 2006;72:263-73.

41. Ward AJW, Hart PJB, Krause J. The effects of habitat- and diet-based cues on association preferences in three-spined sticklebacks. Behav Ecol. 2004;15(6):925-9.

42. Watson PJ, Lighton JRB. Sexual selection and the energetics of copulatory courtship in the Sierra dome spider, Linyphia litigiosa. Anim Behav. 1994:48:615-26.

43. Barske J, Schlinger BA, Wikelski M, Fusani L. Female choice for male motor skills. P R Soc B-Biol Sci. 2011;278:3523-8.

44. Riechert SE. The consequences of being territorial: spiders, a case study. Am Nat. 1981;117:871-92.
45. Barlow GW. Mate choice in the monogamous and polychromatic Midas cichlid, Cichlasoma citrinellum. J Fish Biol. 1986;29:123-33.

46. Jaroensutasinee $M$, Jaroensutasinee $K$. Type of intruder and reproductive phase influence male territorial defence in wild-caught Siamese fighting fish. Behav Proc. 2003;64(1):23-9.

47. Ward G, FitzGerald GJ. Male aggression and female mate choice in the threespine stickleback, Gasterosteus aculeatus L. J Fish Biol. 1987;30:679-90.

48. Dey CJ, O'Connor CM, Gilmour KM, Van Der Kraak G, Cooke SJ. Behavioral and physiological responses of a wild teleost fish to cortisol and androgen manipulation during parental care. Horm Behav. 2010;58(4):599-605.

49. Candolin U. The relationship between signal quality and physical condition: is sexual signalling honest in the three-spined stickleback? Anim Behav. 1999:58:1261-7.

50. Milinski M, Bakker TCM. Female sticklebacks use male colouration as a basis for mate choice and hence avoid parasitised males. Nature. 1990;344:330-3.

51. Johnson S, Candolin U. Predation cost of a sexual signal in the threespine stickleback. Behav Ecol. 2017;28:1160-5.

52. Pike TW, Blount JD, Bjerkeng B, et al. Carotenoids, oxidative stress and female mating preference for longer lived males. P R Soc B-Biol Sci. 2007;274:1591-6.

53. Kim SY, Costa MM, Esteve-Codina A, Velando A. Transcriptional mechanisms underlying life-history responses to climate change in the threespined stickleback. Evol Appl. 2017;10:718-30.

54. Andersson M, Simmons LW. Sexual selection and mate choice. Trends Ecol Evol. 2006:21:296-302.

55. Kim SY, Noguera JC, Velando A. Carry-over effects of early thermal conditions on somatic and germline oxidative damages are mediated by compensatory growth in sticklebacks. J Anim Ecol. 2019;88:473-83.

56. Pike TW, Blount JD, Lindström J, Metcalfe NB. Dietary carotenoid availability, sexual signalling and functional fertility in sticklebacks. Biol Lett. 2010;6:191-3.

57. Álvarez-Quintero N, Velando A, Noguera JC, Kim SY. Environment-induced changes in reproductive strategies and their transgenerational effects in the three-spined stickleback. Ecol Evol. 2021;11:771-83.

58. Kim SY, Velando A. Stickleback males increase red coloration and courtship behaviours in the presence of a competitive rival. Ethology. 2014;120:502-10

59. Bakker TCM, Sevenster P. Determinants of dominance in male sticklebacks (Gasterosteus aculeatus L.). Behaviour. 1983;86:55-71.

60. Pike TW, Blount JD, Lindström J, Metcalfe NB. Availability of non-carotenoid antioxidants affects the expression of a carotenoid-based sexual ornament. Biol Lett. 2007;3:353-6.

61. Hiermes M, Rick IP, Mehlis M, Bakker TCM. The dynamics of color signals in male threespine sticklebacks Gasterosteus aculeatus. Curr Zool. 2016:62:23-31.

62. Kraak SBM, Bakker TCM. Mutual mate choice in sticklebacks: attractive males choose big females, which lay big eggs. Anim Behav. 1998;56:859-66.

63. Reynolds JD, Gross MR. Female mate preference enhances offspring growth and reproduction in a fish, Poecilia reticulata. P R Soc B-Biol Sci. 1992;250:57-62.

64. Norris K. Heritable variation in a plumage indicator of viability in male great tits Parus major. Nature. 1993:362:537-9.

65. Møller AP. Male ornament size as a reliable cue to enhanced offspring viability in the barn swallow. P Natl Acad Sci USA. 1994;91:6929-32.

66. Petrie M. Improved growth and survival of offspring of peacocks with more elaborate trains. Nature. 1994;371:598-9.

67. Barber I, Arnott SA, Braithwaite VA, et al. Indirect fitness consequences of mate choice in sticklebacks: offspring of brighter males grow slowly but resist parasitic infections. P R Soc B-Biol Sci. 2001:268:71-6.

68. Kekäläinen J, Huuskonen H, Tuomaala M, Kortet R. Both male and female sexual ornaments reflect offspring performance in a fish. Evolution. 2010;64:3149-57

69. Simmons LW, Holley R. Offspring viability benefits but no apparent costs of mating with high quality males. Biol Lett. 2011;7:419-21.

70. Weir LK, Grant JWA. Courtship rate signals fertility in an externally fertilizing fish. Biol Lett. 2010;6:727-31.

71. Hoelzer GA. The good parent model of sexual selection. Anim Behav. $1989 \cdot 38 \cdot 1067-78$ 
72. Kim SY, Metcalfe NB, Velando A. A benign juvenile environment reduces the strength of antagonistic pleiotropy and genetic variation in the rate of senescence. J Anim Ecol. 2016;85:705-14.

73. Álvarez-Quintero N, Velando A, Kim SY. Smart mating: the cognitive ability of females influences their preference for male cognitive ability. Behav Ecol. 2021. https://doi.org/10.1093/beheco/arab052.

74. Polak M, Starmer WT. Parasite-induced risk of mortality elevates reproductive effort in male Drosophila. P R Soc B-Biol Sci. 1998;265:2197-201.

75. Barber I, Arnott SA. Split-clutch IVF: a technique to examine indirect fitness consequences of mate preferences in sticklebacks. Behaviour. 2000:137:1129-40.

76. Friard O, Gamba M. BORIS: a free, versatile open-source event-logging software for video/audio coding and live observations. Methods Ecol Evol. 2016;7:1325-30.

77. Auer SK, Dick CA, Metcalfe NB, Reznick DN. Metabolic rate evolves rapidly and in parallel with the pace of life history. Nat Commun. 2018;9:1-6.

78. Mangiafico SS. Summary and analysis of extension program evaluation in $R$, version 1.18.8. 2016.

79. Stoffel MA, Nakagawa S, Schielzeth H. rptR: repeatability estimation and variance decomposition by generalized linear mixed-effects models. Methods Ecol Evol. 2017;8:1639-44.

\section{Publisher's Note}

Springer Nature remains neutral with regard to jurisdictional claims in published maps and institutional affiliations.

- fast, convenient online submission

- thorough peer review by experienced researchers in your field

- rapid publication on acceptance

- support for research data, including large and complex data types

- gold Open Access which fosters wider collaboration and increased citations

- maximum visibility for your research: over 100M website views per year

At BMC, research is always in progress.

Learn more biomedcentral.com/submissions 